\title{
Comparative Solid Phase Photocatalytic Degradation of Polythene Films with Doped and Undoped $\mathrm{TiO}_{2}$ Nanoparticles
}

\author{
Wasim Asghar, ${ }^{1}$ Ishtiaq A. Qazi, ${ }^{1}$ Hassan Ilyas, ${ }^{1}$ Aftab Ahmad Khan, ${ }^{2}$ M. Ali Awan, ${ }^{1}$ \\ and M. Rizwan Aslam ${ }^{1}$ \\ ${ }^{1}$ Institute of Environmental Science and Engineering, School of Civil and Environmental Engineering, \\ National University of Sciences and Technology (NUST), Sector H-12, Islamabad 44000, Pakistan \\ ${ }^{2}$ Advanced Engineering Research Organization (AERO), Hassan Abdal 43730, Pakistan
}

Correspondence should be addressed to Wasim Asghar, wasim@iese.edu.pk

Received 19 February 2010; Accepted 14 April 2010

Academic Editor: Bo Zou

Copyright (c) 2011 Wasim Asghar et al. This is an open access article distributed under the Creative Commons Attribution License, which permits unrestricted use, distribution, and reproduction in any medium, provided the original work is properly cited.

\begin{abstract}
Comparative photocatalytic degradation of polythene films was investigated with undoped and metal (Fe, Ag, and Fe/Ag mix) doped $\mathrm{TiO}_{2}$ nanoparticles under three different conditions such as UV radiation, artificial light, and darkness. Prepared photocatalysts were characterized by XRD, SEM, and EDS techniques. Photocatalytic degradation of the polythene films was determined by monitoring their weight reduction, SEM analysis, and FTIR spectroscopy. Weight of PE films steadily decreased and led to maximum of $14.34 \%$ reduction under UV irradiation with $\mathrm{Fe} / \mathrm{Ag}$ mix doped $\mathrm{TiO}_{2}$ nanoparticles and maximum of $14.28 \%$ reduction under artificial light with $\mathrm{Ag}$ doped $\mathrm{TiO}_{2}$ nanoparticles in 300 hrs. No weight reduction was observed under darkness. Results reveal that polythene- $\mathrm{TiO}_{2}$ compositing with metal doping has the potential to degrade the polythene waste under irradiation without any pollution.
\end{abstract}

\section{Introduction}

Titanium dioxide $\left(\mathrm{TiO}_{2}\right)$ is one of the most well-known efficient photocatalysts. The capability of $\mathrm{TiO}_{2}$-based photocatalyst to degrade gaseous and aqueous contamination makes it a good candidate for use in air clean up and water purification. However, most applications so far are limited to UV light irradiation because the light absorption edge of pure $\mathrm{TiO}_{2}$ is lower than $380 \mathrm{~nm}$. Therefore, the development of modified titania with high activity under visible light $(\lambda>380 \mathrm{~nm})$ should take full advantage of the main part of the solar spectrum (mostly 400-600 nm) [1].

The most promising approach of activation of $\mathrm{TiO}_{2}$, in the visible light region, is modification of its chemical structure to shift the absorption spectrum to the visible light region [2-4]. This type of modification involves introduction of doping with metal and nonmetal species. To prepare an effective visible light, active photocatalyst doping should produce states in the band gap of $\mathrm{TiO}_{2}$ that absorbs visible light [5].
The process of recycling polymers is expensive and time consuming; only a small percentage of the plastic waste is currently being recycled [6]. Biodegradable plastics have shown considerable promise in this context $[7,8]$. However, the biodegradable plastics till now cannot completely solve the problem due to their chemical stability and nonaffordable cost [9]. More recently, photo degradation of plastics has also started receiving attention. The composition of plastic and $\mathrm{TiO}_{2}$ nanoparticles (NPs) has been proven to be a new and useful way to decompose solid polymer in open air. Investigations on the photo degradation of polyvinyl chloride (PVC), polystyrene (PS), and polythene (PE) have been carried out [10-12]. More specifically, a few recent reports describe the use of $\mathrm{TiO}_{2}$ and goethite and so forth as the photocatalyst for oxidative degradation of PE with very encouraging results $[13,14]$.

The present study was focused on solid phase photocatalytic degradation of polyethylene plastic with $\mathrm{TiO}_{2}$ as photocatalyst and $\mathrm{Fe}, \mathrm{Ag}$ metals as dopants. $\mathrm{PE}-\mathrm{TiO}_{2}$ composite films were prepared and their photocatalytic 
degradation under ultraviolet irradiation, artificial light and darkness was studied.

\section{Materials and Methods}

2.1. Chemical Reagents. GPR $\mathrm{TiO}_{2}$ (BDH Chemicals Ltd., England) and chemical reagents like iron (III) nitrate nonahydrate, silver nitrate, and cyclohexane (Merck, Germany) were used in this study. All chemicals were of analytical grade and used without further purification. PE originating from QAPCO Petrochemical Corp., Qatar was purchased from the local market.

2.2. Preparation of Doped $\mathrm{TiO}_{2}$ Nanoparticles. Fe doped, Ag doped, and $\mathrm{Fe} / \mathrm{Ag}$ mix doped $\mathrm{TiO}_{2} \mathrm{NPs}$ were prepared by the liquid impregnation (LI) method by the following steps. $3 \mathrm{~g}$ of GPR $\mathrm{TiO}_{2}$ was added to $100 \mathrm{~mL}$ distilled water and then the required amount of iron (III) nitrate nonahydrate, for doping, was added to $\mathrm{TiO}_{2}$ suspension, where the $\mathrm{Fe}$ concentration was of $1 \%$ (mole ratio) versus $\mathrm{TiO}_{2}$. The slurry was stirred well and allowed to rest for 24 hours and then dried in an air oven at $100^{\circ} \mathrm{C}$ for 12 hours [15]. The dried solids were ground in an agate mortar and calcinated at $500^{\circ} \mathrm{C}$ for 3 hours in a furnace. Same steps were repeated with silver nitrate as precursor for $\mathrm{Ag}$ doped $\mathrm{TiO}_{2}$ NPs where the Ag concentration was of $1 \%$ (mole ratio) versus $\mathrm{TiO}_{2}$. For Fe/Ag mix doped $\mathrm{TiO}_{2}$, iron (III) nitrate nonahydrate and silver nitrate were used as the precursors for Fe and Ag, respectively. The mole ratio, with respect to $\mathrm{TiO}_{2}$, for both $\mathrm{Fe}$ and $\mathrm{Ag}$ was $0.5 \%$ each. GPR $\mathrm{TiO}_{2}$ was calcinated at $500^{\circ} \mathrm{C}$ for 3 hours when used as undoped $\mathrm{TiO}_{2} \mathrm{NPs}$ source.

2.3. Preparation of $\mathrm{PE}-\mathrm{TiO}_{2}$ Composite Films. Polymer stock solution was prepared by dissolving $1 \mathrm{~g}$ of PE in $100 \mathrm{~mL}$ cyclohexane at $70^{\circ} \mathrm{C}$ under vigorous stirring for 60 minutes. Following this, $\mathrm{TiO}_{2}$ NPs were suspended uniformly in the above solution to give $1.0 \%$ (weight) contents with respect to the total mass of PE. An aliquot of $20 \mathrm{~mL}$ of ${\mathrm{PE}-\mathrm{TiO}_{2}}_{2}$ prepared solution was spread as a disc $(r=4 \mathrm{~cm})$ on a glass plate and first dried for 20 minutes at $70^{\circ} \mathrm{C}$, then dried for 48 hours at room temperature [16]. Weight of the resulting $\mathrm{PE}-\mathrm{TiO}_{2}$ composite films was 0.2 gm approximately. Same procedure was followed to prepare the composite films of PE with $\mathrm{Fe}, \mathrm{Ag}$, and $\mathrm{Fe} / \mathrm{Ag}$ mix doped $\mathrm{TiO}_{2}$ NPs.

\section{Characterization}

\subsection{Characterization of $\mathrm{TiO}_{2}$ Nanoparticles}

3.1.1. X-Ray Diffraction Analysis. Crystal size of the prepared photocatalyst was studied by powder XRD technique. X-ray diffraction patterns were obtained on JEOL JDX-II X-ray diffractometer using $\mathrm{Cu}-\mathrm{K}_{\alpha}$ radiation at an angle of $2 \theta$ from $10^{\circ}$ to $80^{\circ}$. The crystallite size was determined from the X-ray diffraction patterns, based on the Scherer equation [14]

$$
L=\frac{k \lambda}{\beta \cos \theta}
$$

TABLE 1: Crystal sizes of doped and undoped $\mathrm{TiO}_{2}$ nanoparticles.

\begin{tabular}{llcc}
\hline \multirow{2}{*}{ Sr. no. } & \multirow{2}{*}{ Sample name } & \multicolumn{2}{c}{ Crystal size (nm) } \\
& & Maximum & Minimum \\
\hline 1 & Undoped $\mathrm{TiO}_{2}$ & 42.52 & 26.72 \\
2 & Fe doped $\mathrm{TiO}_{2}$ & 42.52 & 26.72 \\
3 & Ag doped $\mathrm{TiO}_{2}$ & 42.52 & 11.27 \\
4 & Fe/Ag mix doped $\mathrm{TiO}_{2}$ & 42.52 & 20.09 \\
\hline
\end{tabular}

where $k$ is a shape factor $=0.9, \lambda$ is the radiation wavelength $=$ $1.54051^{\circ} \mathrm{A}, \theta$ is the Bragg angle, $\beta=$ full width of a diffraction line at one half of maximum intensity in radian.

3.1.2. SEM Study. SEM study of doped and undoped $\mathrm{TiO}_{2}$ NPs was conducted with JEOL JSM-6460 scanning electron microscope to see the distribution of metal on the surface of $\mathrm{TiO}_{2}$ in doped species.

3.1.3. EDS Analysis. Energy dispersive spectroscopic (EDS) analysis was conducted with Oxford INCA X-sight 200 to perform the quantitative analysis of the $\mathrm{TiO}_{2}$ both in doped and undoped conditions.

\subsection{Characterization of Polythene Films}

3.2.1. Weight Reduction Analysis. Photo degradation study of the PE films was conducted based on weight reduction. Weighing balance, with 0.0001 gm sensitivity (Denver Instrument Company XE Series, model 100A) was used for weight measurements.

3.2.2. Surface Morphology and Thickness Analysis. Surface morphology \& thickness analysis of PE films was conducted with JEOL JSM-6460 scanning electron microscope before and after the 300 hours of UV exposure.

3.2.3. FTIR Analysis. To get the qualitative analysis of the PE films, FTIR analysis was conducted with Perkin Elmer Spectrum BX-II FTIR spectrometer before and after irradiation.

\section{Results and Discussions}

\subsection{Characterization of $\mathrm{TiO}_{2}$ Nanoparticles}

4.1.1. X-Ray Diffraction Analysis. Table 1 shows the results of $\mathrm{X}$-ray diffraction analysis, which demonstrate a variation in nanoparticles size as compared to a previous study [15]. This study reported that the average size of prepared Ag doped $\mathrm{TiO}_{2}$ NPs was $14 \mathrm{~nm}$ while Ag doped $\mathrm{TiO}_{2}$ NPs prepared in current study were in the 11.27 to $42.52 \mathrm{~nm}$ range. This difference may be due to the $\mathrm{TiO}_{2}$ source, as GPR $\mathrm{TiO}_{2}$ was used as $\mathrm{TiO}_{2}$ source in the current study while P-25 Degussa was used in the previous one. Figure 1 shows the respective XRD patterns of doped and undoped $\mathrm{TiO}_{2} \mathrm{NPs}$. 


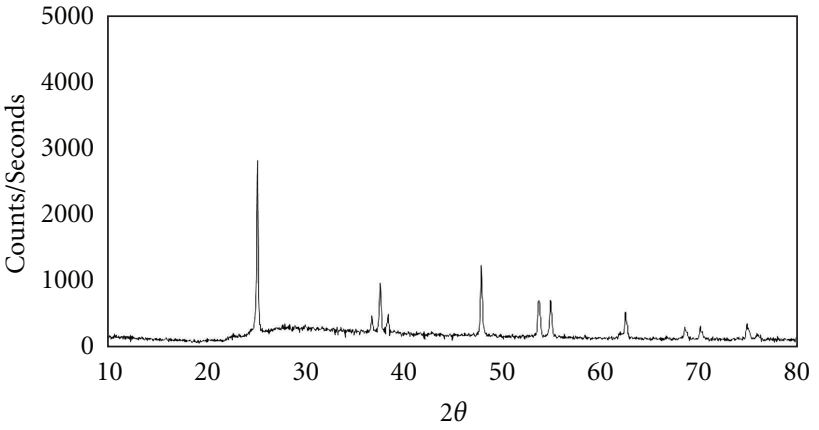

(a)

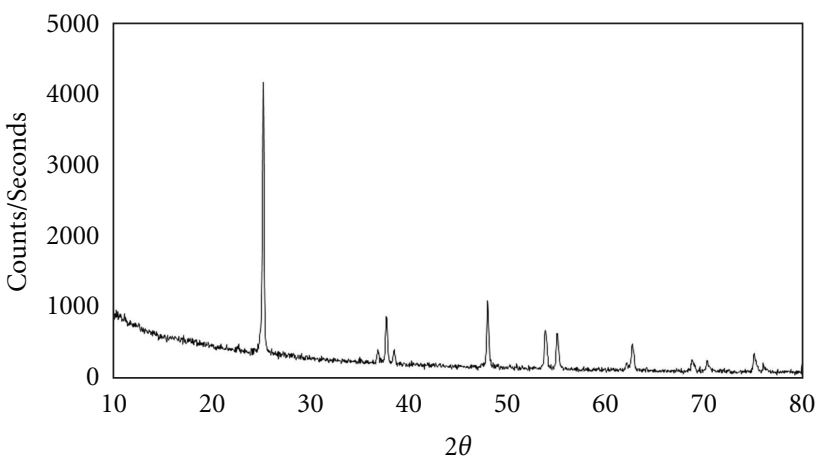

(b)

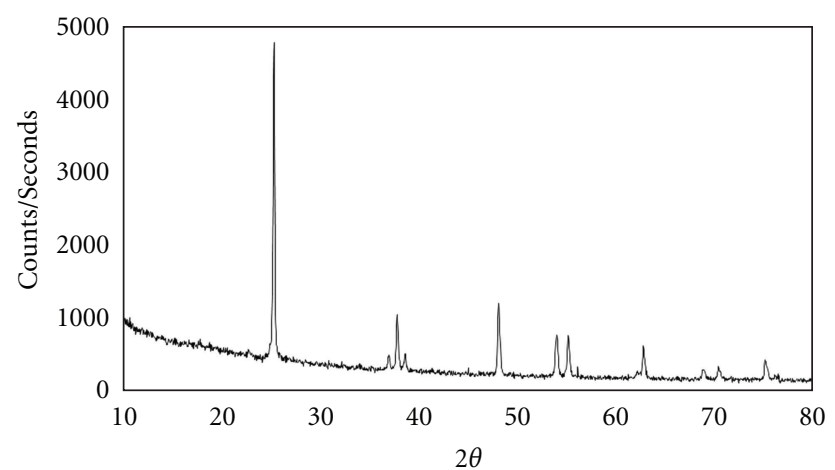

(c)

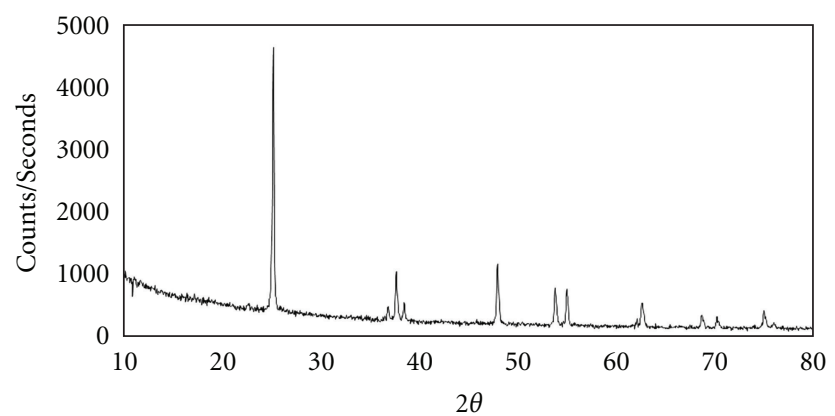

(d)

FIgure 1: XRD patterns: (a) undoped $\mathrm{TiO}_{2}$, (b) Fe doped $\mathrm{TiO}_{2}$, (c) Ag doped $\mathrm{TiO}_{2}$, and (d) Fe/Ag mix doped $\mathrm{TiO}_{2}$.
TABLE 2: EDS analysis of doped and undoped $\mathrm{TiO}_{2}$ nanoparticles.

\begin{tabular}{llccc}
\hline \multirow{2}{*}{ Sr. no. } & \multirow{2}{*}{ Sample name } & \multicolumn{3}{c}{ Elements in percent ratio } \\
& & $\mathrm{Ti}$ & $\mathrm{Fe}$ & $\mathrm{Ag}$ \\
\hline 1 & Undoped $\mathrm{TiO}_{2}$ & 100.00 & - & - \\
2 & Fe doped $\mathrm{TiO}_{2}$ & 99.08 & 0.92 & - \\
3 & $\mathrm{Ag}$ doped $\mathrm{TiO}_{2}$ & 99.09 & - & 0.91 \\
4 & $\mathrm{Fe} /$ Ag mix doped $\mathrm{TiO}_{2}$ & 98.99 & 0.48 & 0.53 \\
\hline
\end{tabular}

TABle 3: Photo catalyzed weight reduction (maximum) of pure PE films and $\mathrm{PE}-\mathrm{TiO}_{2}$ composite films.

\begin{tabular}{llccc}
\hline \multirow{2}{*}{ Sr. no. Sample name } & \multicolumn{4}{c}{ Maximum weight reduction (\%) } \\
& & UV & Artificial light & Dark \\
\hline 1 & Pure $\mathrm{PE}$ & 3.32 & 0.65 & No reduction \\
2 & $\mathrm{PE}+\mathrm{TiO}_{2}$ & 10.6 & 6.51 & $=$ do $=$ \\
3 & $\mathrm{PE}+\mathrm{Fe}$ doped $\mathrm{TiO}_{2}$ & 13.49 & 11.9 & $=$ do $=$ \\
4 & $\mathrm{PE}+$ Ag doped $\mathrm{TiO}_{2}$ & 13.75 & 14.28 & $=$ do $=$ \\
5 & $\begin{array}{l}\mathrm{PE}+\mathrm{Fe} / \mathrm{Ag}^{2} \text { mix } \\
\text { doped } \mathrm{TiO}_{2}\end{array}$ & 14.34 & 13.18 & $=$ do $=$ \\
\hline
\end{tabular}

4.1.2. SEM Analysis. Figure 2 shows the images of doped and undoped $\mathrm{TiO}_{2}$ NPs obtained with scanning electron microscope. These images show that the distribution of the dopant metals on the surface of $\mathrm{TiO}_{2}$ is not uniform and doped species contain irregular shaped particles which are aggregations of tiny crystals. SEM analysis verifies the results of previous reported work [15].

4.1.3. EDS Analysis. Figure 3 shows the EDS spectra of doped and undoped $\mathrm{TiO}_{2}$ NPs. EDS analysis shows that the percent composition is not consistent in the doped $\mathrm{TiO}_{2}$ NPs. It varies from point to point showing that composition of the prepared NPs is not homogeneous. It confirms the SEM results. Average composition of doped and undoped NPs is given as in Table 2.

\subsection{Characterization of Polythene Films}

4.2.1. Weight Reduction Analysis. Pure $\mathrm{PE}$ and $\mathrm{PE}-\mathrm{TiO}_{2}$ composite films were exposed with UV and artificial light constantly for 300 hours under ambient conditions. Parallel studies were conducted with no irradiation under darkness. $\mathrm{TiO}_{2}$ photocatalyst absorbs only UV light $(\lambda<380 \mathrm{~nm})$, thus only UV light plays a role in solar degradation of PE$\mathrm{TiO}_{2}$ composite plastic. In order to reveal the photocatalytic degradation behavior the photo degradation reaction was conducted under ambient air in a lamp-housing box $(50 \mathrm{~cm}$ $\times 40 \mathrm{~cm} \times 30 \mathrm{~cm}$ ) as shown in Figure 4. Pure PE and PE$\mathrm{TiO}_{2}$ doped \& undoped composite films were irradiated by two 6W UVL-56 UV lamps. The primary wavelength of the lamps was $365 \mathrm{~nm}$ and the light intensity measured with ABM Model 150 digital intensity meter was $1.4 \mathrm{~mW} / \mathrm{cm}^{2}$ at $3 \mathrm{~cm}$ away from the lamps. For artificial light source a common household energy saver bulb of TORNADO 24 watt was used. Table 3 shows the summary of the photo catalyzed 


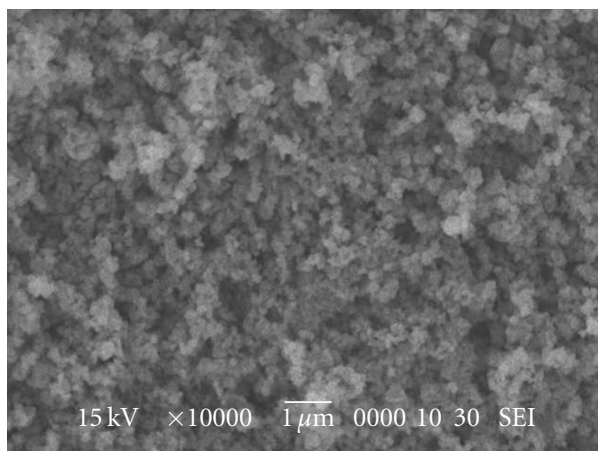

(a)

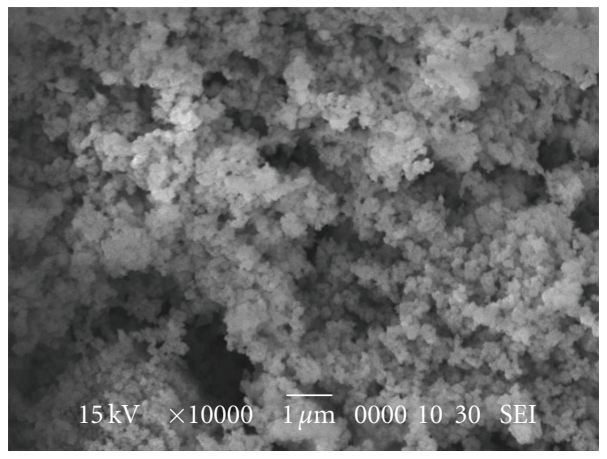

(c)

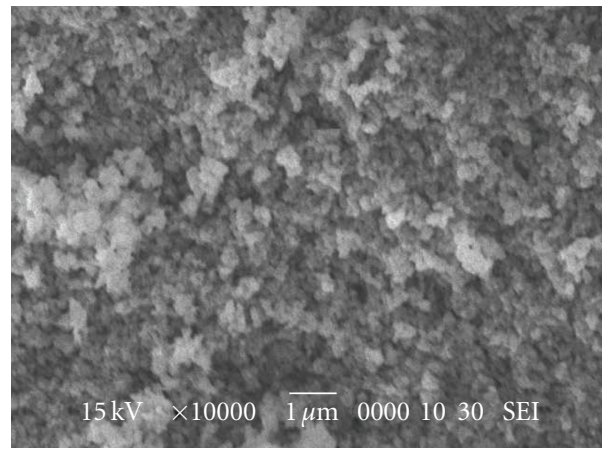

(b)

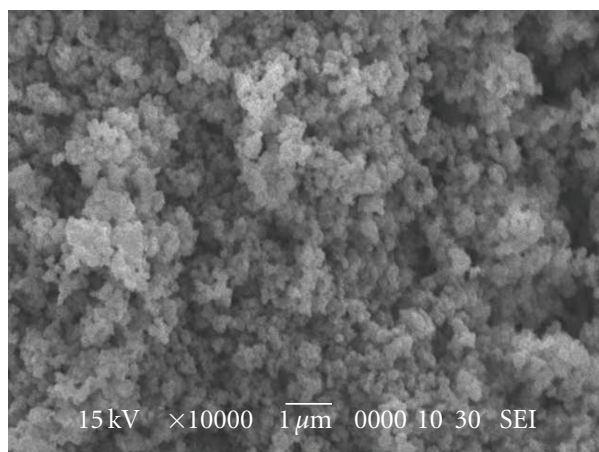

(d)

Figure 2: SEM images of $\mathrm{TiO}_{2}$ NPs: (a) undoped $\mathrm{TiO}_{2}$, (b) Fe doped $\mathrm{TiO}_{2}$, (c) Ag doped $\mathrm{TiO}_{2}$, and (d) Fe/Ag mix doped TiO .

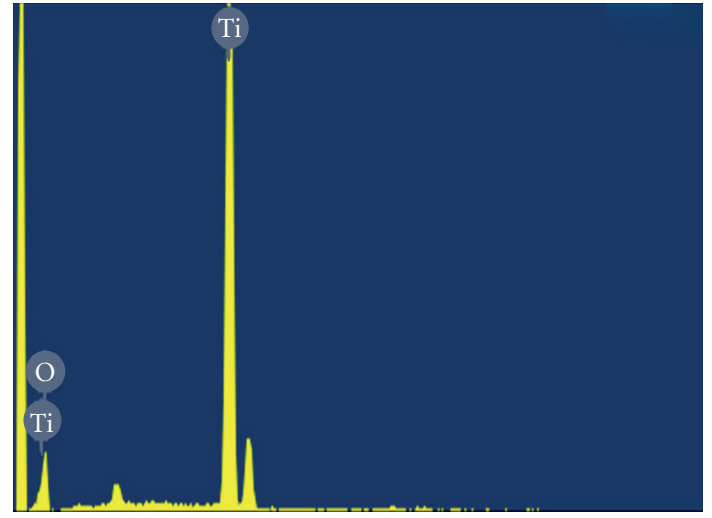

(a)

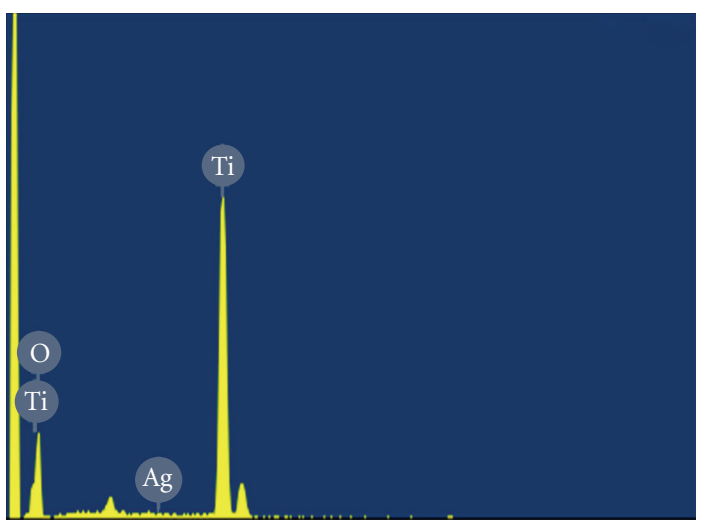

(c)

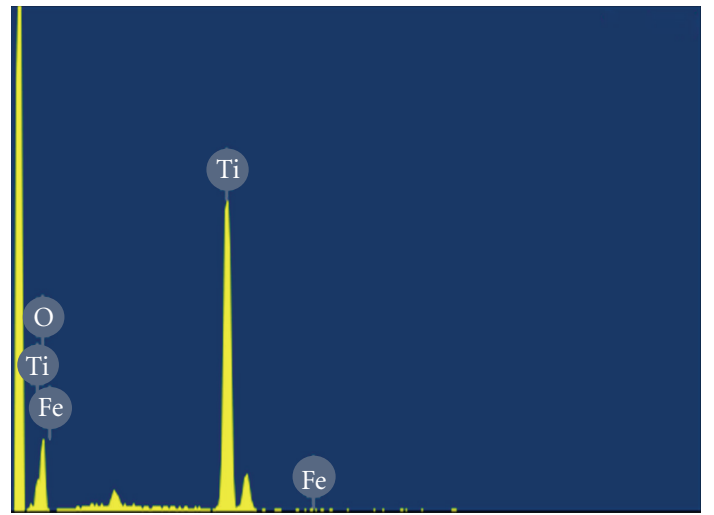

(b)

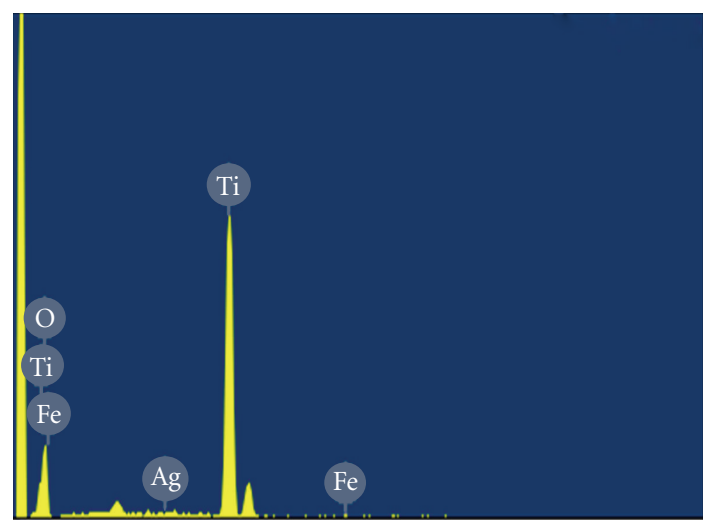

(d)

Figure 3: EDS spectra of $\mathrm{TiO}_{2}$ NPs: (a) undoped $\mathrm{TiO}_{2}$, (b) Fe doped $\mathrm{TiO}_{2}$, (c) Ag doped $\mathrm{TiO}_{2}$, and (d) Fe/Ag mix doped TiO . 


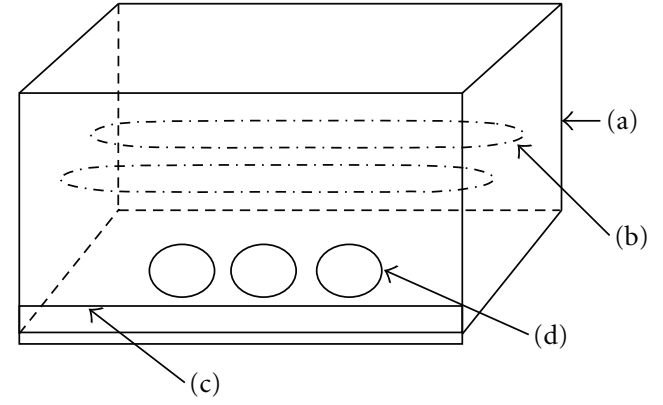

Figure 4: Schematic diagram of photocatalytic reactor: (a) lamp housing box, (b) two ultraviolet lamps, (c) air and water inlet, and (d) sample dishes.

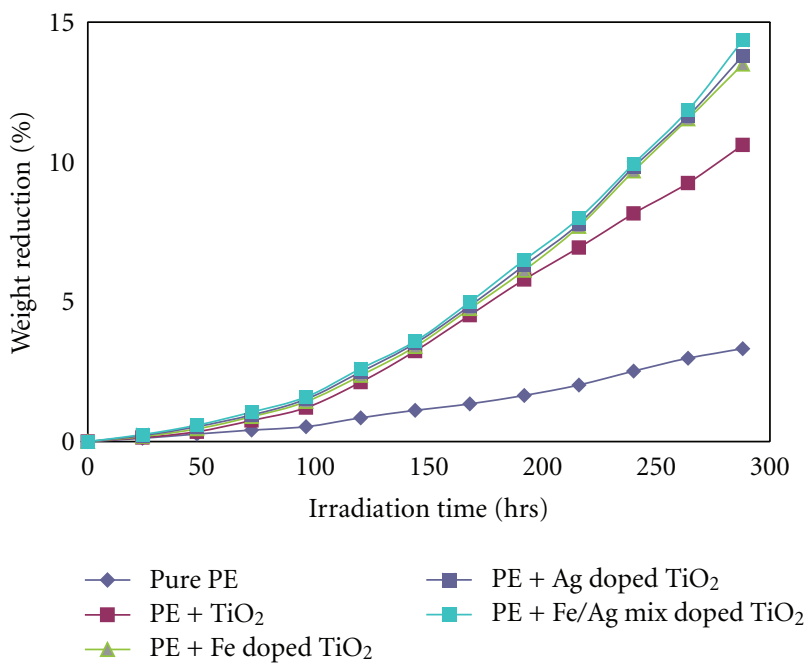

FIGURE 5: Effect of UV irradiation on the photocatalytic degradation of PE films.

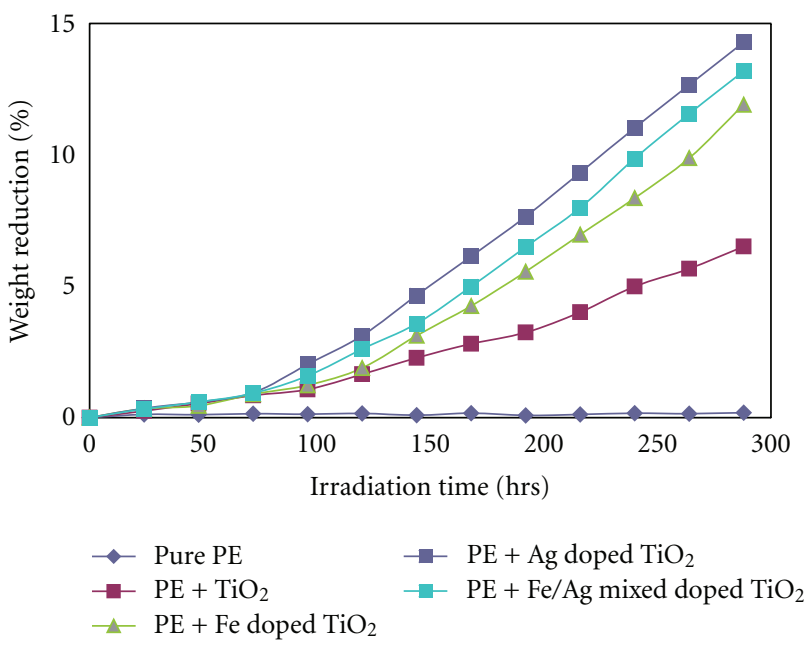

FIGURE 6: Effect of artificial light on the photocatalytic degradation of PE films. weight loss of pure PE film and $\mathrm{PE}-\mathrm{TiO}_{2}$ composite films with $\mathrm{Fe}, \mathrm{Ag}$, and $\mathrm{Fe} / \mathrm{Ag}$ mix doping under UV irradiation, artificial light and darkness. Figure 5 shows the details of percent weight reduction under UV light and Figure 6 shows the details of percent weight reduction under artificial light. Negligible change was detected in all PE films with or without $\mathrm{TiO}_{2}$ under darkness.

4.2.2. Polythene Film Thickness. Almost twofold increase in the thickness of polythene films was observed after UV irradiation for 300 hours from $22-28 \mu \mathrm{m}$ range to $58-61 \mu \mathrm{m}$ range as shown in Figure 7. This increase in thickness after degradation may possibly be due to the released species like $\mathrm{CO}_{2}$ causing swelling, affecting the overall thickness of the PE films.

4.2.3. Surface Morphology of Polythene Films. Scanning electron microscope analysis was carried out to observe the surface changes of the films following photo degradation. Figures 8 (a) and 8 (b) show that the surface of the PE film was smooth before UV irradiation but after UV exposure, due to photo degradation, cavities appeared randomly on the surface of the film. Figures $8(\mathrm{c}), 8(\mathrm{~d}), 8(\mathrm{e})$, and $8(\mathrm{f})$ show the texture of PE films with undoped $\mathrm{TiO}_{2}, \mathrm{Fe}$ doped $\mathrm{TiO}_{2}$, Ag doped $\mathrm{TiO}_{2}$ and $\mathrm{Fe} / \mathrm{Ag}$ mix doped $\mathrm{TiO}_{2}$ under UV irradiation, respectively. After irradiation, there were some cavities in the PE film which had also been observed by other workers [14]. The formation of these cavities might be due to the escape of volatile products from $\mathrm{PE}$ matrix. More cavities were found on the surface of $\mathrm{PE}-\mathrm{TiO}_{2}$ composite film. Figures $8(\mathrm{c}), 8(\mathrm{~d}), 8(\mathrm{e})$, and $8(\mathrm{f})$ show that the degradation is greater than that of $\mathrm{PE}-\mathrm{TiO}_{2}$ composite film. These results were in accordance with the weight loss data shown in Figures 7 and 8. SEM images suggested that the degradation of $\mathrm{PE}$ matrix started from $\mathrm{PE}-\mathrm{TiO}_{2}$ interface and led to the formation of cavities around $\mathrm{TiO}_{2}$ particles. It implied that the active oxygen species generated on $\mathrm{TiO}_{2}$ surface diffused and degraded the polymer matrix. This is further strengthened by the thickness analysis of the PE films.

4.2.4. Spectroscopic Analysis. Figure 9 shows the FTIR spectra of pure PE films before and after irradiation and $\mathrm{PE}-\mathrm{TiO}_{2}$ (doped and undoped) composite films after UV irradiation. Spectrum of the PE film before irradiation show the characteristic absorption peaks of long alkyl chain in the region of $2919 \mathrm{~cm}^{-1}, 2857 \mathrm{~cm}^{-1}, 1475 \mathrm{~cm}^{-1}$, and $715 \mathrm{~cm}^{-1}$. Figures 9(b), 9(c), 9(d), 9(e), and 9(f) show the FTIR spectra of the PE, PE-TiO 2 , PE-Fe doped $\mathrm{TiO}_{2}, \mathrm{PE}-\mathrm{Ag}$ doped $\mathrm{TiO}_{2}$, and $\mathrm{PE}-\mathrm{Fe} / \mathrm{Ag}$ mix doped $\mathrm{TiO}_{2}$ after irradiation, respectively. There were new absorption peaks for composite films in the region of $1716 \mathrm{~cm}^{-1}, 1629 \mathrm{~cm}^{-1}$, and $1175 \mathrm{~cm}^{-1}$, which could be assigned to $\mathrm{C}=\mathrm{O}, \mathrm{C}=\mathrm{C}$ and $\mathrm{C}-\mathrm{O}$ stretching vibrations, respectively [10]. The Peak at $3507 \mathrm{~cm}^{-1}$ can be assigned to $-\mathrm{OH}$ stretching that may be formed by the hydrolysis reaction. 


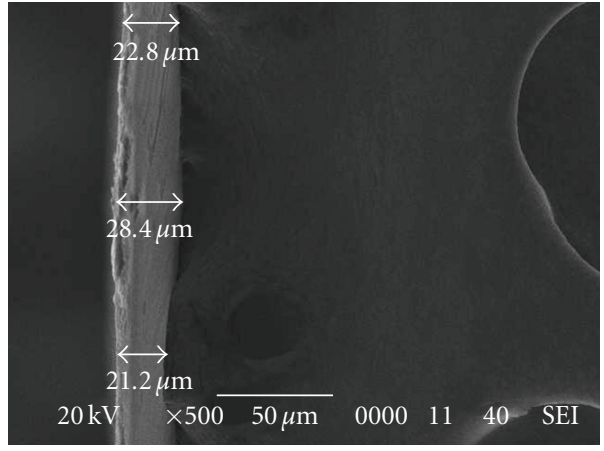

(a)

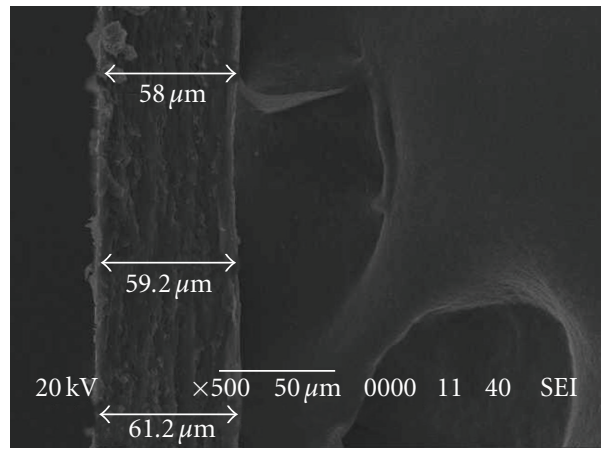

(b)

FIGURE 7: Thickness of PE films: (a) before and (b) after irradiation.

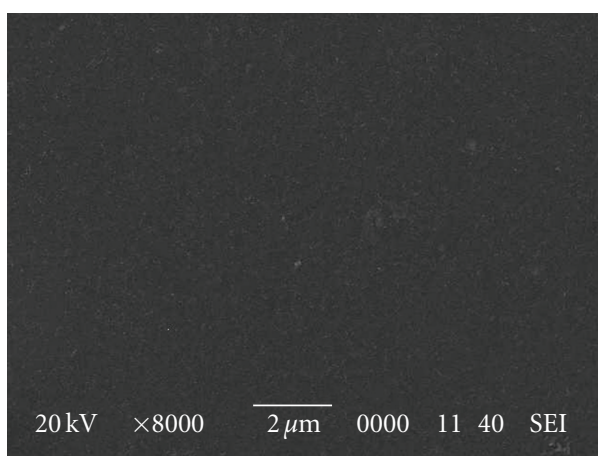

(a)

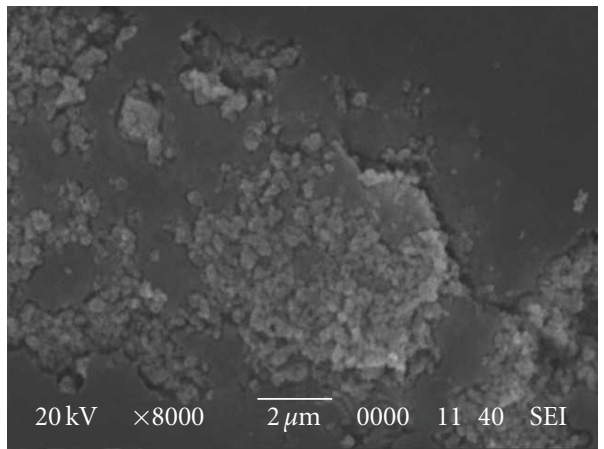

(c)

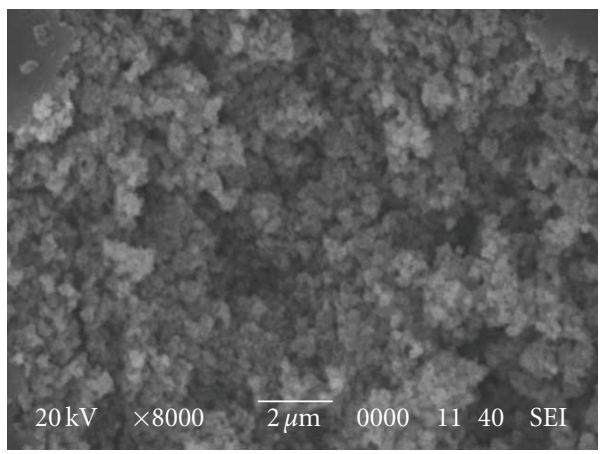

(e)

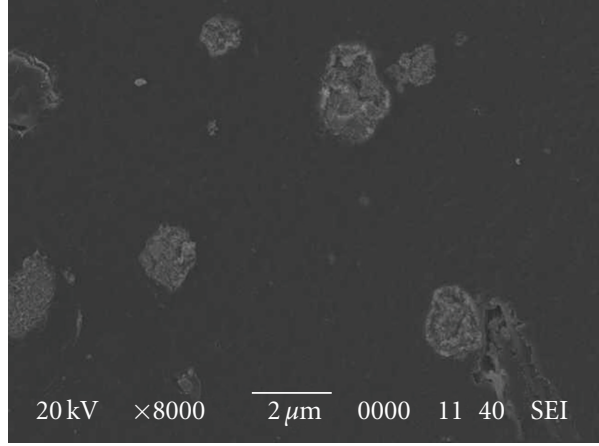

(b)

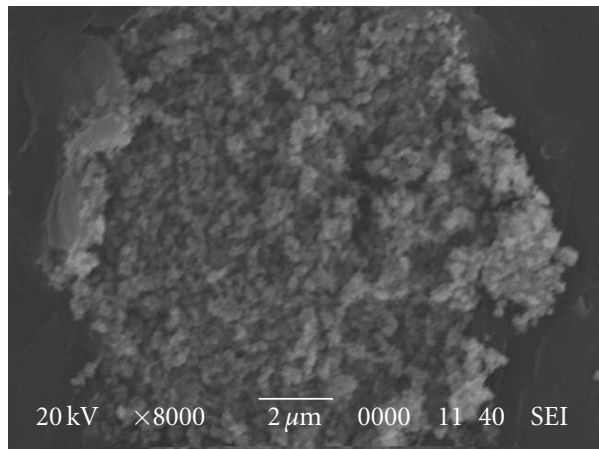

(d)

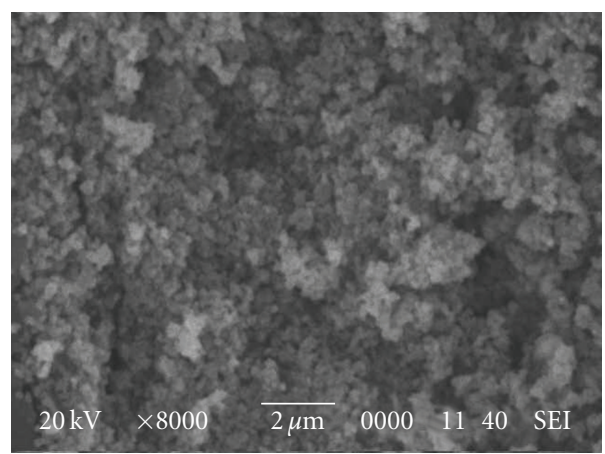

(f)

Figure 8: SEM images of PE films before and after irradiation: (a) PE film before irradiation, (b) $\mathrm{PE}$ film after irradiation, (c) $\mathrm{PE}$-TiO $_{2}$ film after irradiation, (d) PE-Fe doped $\mathrm{TiO}_{2}$ film after irradiation, (e) $\mathrm{PE}-\mathrm{Ag}$ doped $\mathrm{TiO}_{2}$ film after irradiation, and (f) $\mathrm{PE}-\mathrm{Fe} / \mathrm{Ag}$ mix doped TiO${ }_{2}$ film after irradiation. 


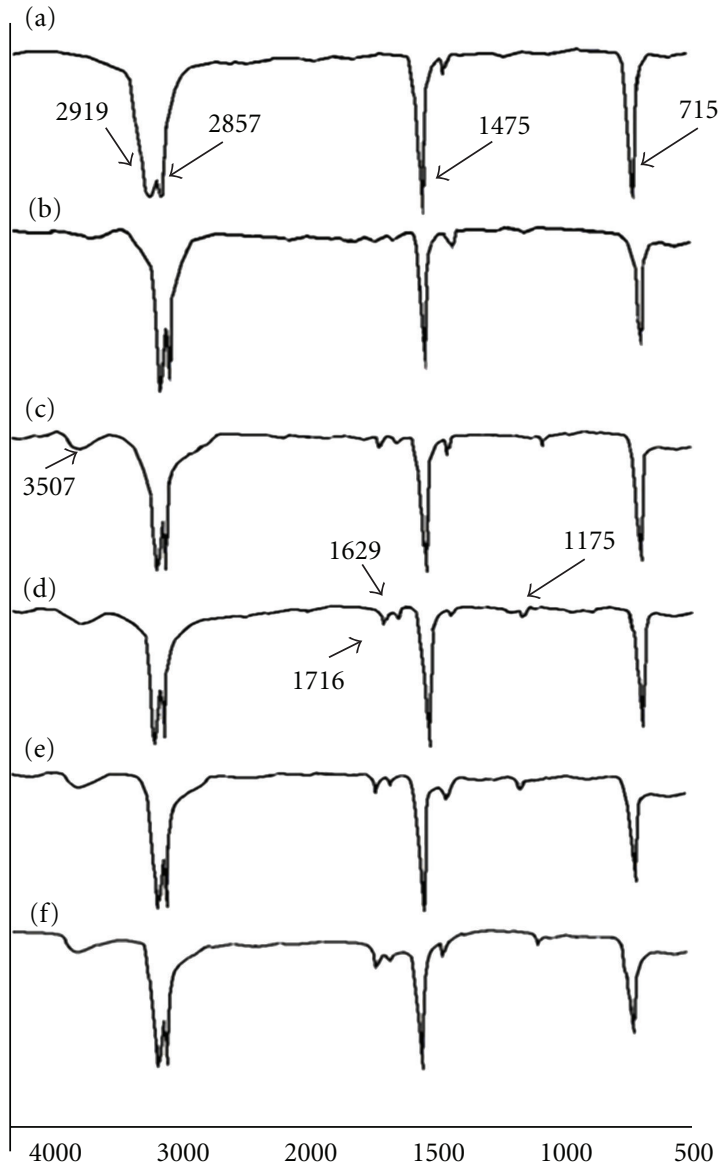

FIGURE 9: FTIR spectra of PE films before and after irradiation: (a) $\mathrm{PE}$ film before irradiation, (b) PE film after irradiation, (c) $\mathrm{PE}-\mathrm{TiO}_{2}$ film after irradiation, (d) $\mathrm{PE}-\mathrm{Fe}$ doped $\mathrm{TiO}_{2}$ film after irradiation, (e) $\mathrm{PE}-\mathrm{Ag}$ doped $\mathrm{TiO}_{2}$ film after irradiation, and (f) $\mathrm{PE}-\mathrm{Fe} / \mathrm{Ag}$ mix doped $\mathrm{TiO}_{2}$ film after irradiation.

4.2.5. Degradation Mechanism of Polythene Films. Photo degradation of pure PE has been extensively studied [17]. The reaction of pure PE film under UV irradiation occurs via direct absorption of photons by the PE macromolecule to create excited states and then undergo chain scission, branching, cross-linking and oxidation reactions [18]. For composite films, photocatalytic degradation is the main reaction, which is quite different from the photolytic degradation of pure PE film. For $\mathrm{PE}-\mathrm{TiO}_{2}$, the photo degradation of PE mainly happens on the film surface where electrons or holes combine with adsorbed oxygen molecules or hydroxyl ion to produce $\mathrm{O}_{2}{ }^{-}$or $\cdot \mathrm{OH}$, two very important reactive oxygen species for the degradation of $\mathrm{PE}$. In the photocatalytic degradation of $\mathrm{PE}-\mathrm{TiO}_{2} / \mathrm{Fe} / \mathrm{Ag}$, not only $\mathrm{O}_{2}{ }^{-}$and $\cdot \mathrm{OH}$ but also the holes that are generated in the ground state of $\mathrm{Fe} / \mathrm{Ag}$ play an important role. Efficient holes production occurs in the ground state of Fe/Ag under irradiation. Although holes in the ground state of $\mathrm{Fe} / \mathrm{Ag}$ have lower oxidative ability than those in the valence band of $\mathrm{TiO}_{2}$, it is energetically favorable for these to participate in the oxidation of PE polymer. Further dopants like Fe and $\mathrm{Ag}$ can act as both $\mathrm{h}^{+} / \mathrm{e}^{-}$traps to reduce the recombination rate of $\mathrm{h}^{+} / \mathrm{e}^{-}$pairs and enhance the photocatalytic activity [19]

$$
\begin{aligned}
& \mathrm{TiO}_{2}+\mathrm{h} v \longrightarrow \mathrm{TiO}_{2}\left(\mathrm{e}^{-}+\mathrm{h}^{+}\right) \\
& \mathrm{h}^{+}+-\left(\mathrm{CH}_{2} \mathrm{CH}_{2}\right)-\longrightarrow-\left(\mathrm{CH}_{2} \mathrm{CH}_{2}\right)^{+} \\
& -\left(\mathrm{CH}_{2} \mathrm{CH}_{2}\right)^{+}+\mathrm{O}_{2}^{-} \longrightarrow-\left(\mathrm{C} \cdot \mathrm{HCH}_{2}\right)-+\mathrm{HO}_{2} \cdot \\
& \mathrm{HO}_{2} \cdot+\mathrm{HO}_{2} \cdot \longrightarrow \mathrm{H}_{2} \mathrm{O}_{2}+\mathrm{O}_{2} \\
& \mathrm{H}_{2} \mathrm{O}_{2} \stackrel{\mathrm{h} v}{\longrightarrow} 2 \cdot \mathrm{OH} .
\end{aligned}
$$

Embedded $\mathrm{TiO}_{2}$ NPs can generate enough $\cdot \mathrm{OH}$ to photo degrade inner PE. The active oxygen species described above, initiate the degradation reaction by attacking neighboring polymer chains [7]. The degradation process spatially extends into the polymer matrix through the diffusion of the reactive oxygen species. Once the carbon-centered radicals are introduced in the polymer chain, their successive reactions lead to the chain cleavage with the oxygen incorporation and species containing carbonyl \& carboxyl groups are produced. These intermediates can be further photo catalytically oxidized to $\mathrm{CO}_{2}$ and $\mathrm{H}_{2} \mathrm{O}$ by the aid of reactive oxygen species [20].

\section{Conclusions}

Doping of $\mathrm{TiO}_{2}$ NPs by Liquid Impregnation method alters its characteristics such as particle size and surface morphology. The effect of mix doping is midway between that of the doping effect by a single metal alone. This indicates that metal ratios can be adjusted to get a desired impact for a particular requirement. This idea was implied and verified in the photo degradation of PE under UV and artificial light irradiation. Photo degradation of $\mathrm{PE}-\mathrm{TiO}_{2}$ films occurred at faster rate and was more complete than the simple photo degradation of pure PE films under UV and artificial light irradiation. Among the $\mathrm{PE}-\mathrm{TiO}_{2}$ films, the degradation of doped $\mathrm{TiO}_{2}$ composite film was greater than the undoped $\mathrm{TiO}_{2}$ composite film both under UV and artificial light irradiation. Overall degradation trend can be represented as

$$
\text { PE-doped } \mathrm{TiO}_{2}>\text { PE-undoped } \mathrm{TiO}_{2}>\text { simple PE. }
$$

Catalytic trend among the doped $\mathrm{TiO}_{2}$ NPs under UV irradiation can be represented as

$\mathrm{Fe} / \mathrm{Ag}$ mix doped $\mathrm{TiO}_{2}>\mathrm{Ag}$ doped $\mathrm{TiO}_{2} \cong \mathrm{Fe}$ doped $\mathrm{TiO}_{2}$.

Catalytic trend among the doped $\mathrm{TiO}_{2} \mathrm{NPs}$ under artificial light can be represented as

Ag doped $\mathrm{TiO}_{2}>\mathrm{Fe} / \mathrm{Ag}$ mix doped $\mathrm{TiO}_{2}>\mathrm{Fe}$ doped $\mathrm{TiO}_{2}$.

It is our observation that development of this kind of composite polymer can lead to an environmental friendly polythene product. 


\section{References}

[1] C.-C. Pan and J. C. S. Wu, "Visible-light response Cr-doped $\mathrm{TiO}_{2-X} \mathrm{~N}_{X}$ photocatalysts," Materials Chemistry and Physics, vol. 100, no. 1, pp. 102-107, 2006.

[2] D. Nabi, I. Aslam, and I. A. Qazi, "Evaluation of the adsorption potential of titanium dioxide nanoparticles for arsenic removal," Journal of Environmental Sciences, vol. 21, no. 3, pp. 402-408, 2009.

[3] C. He, Y. Yu, X. Hu, and A. Larbot, "Influence of silver doping on the photocatalytic activity of titania films," Applied Surface Science, vol. 200, no. 1-4, pp. 239-247, 2002.

[4] M. S. Hegde, K. Nagaveni, and S. Roy, "Synthesis, structure and photocatalytic activity of nano $\mathrm{TiO}_{2}$ and nano $\mathrm{Ti}_{1-x} \mathrm{M}_{x} \mathrm{O}_{2-\delta}(\mathrm{M}=\mathrm{Cu}, \mathrm{Fe}, \mathrm{Pt}, \mathrm{Pd}, \mathrm{V}, \mathrm{W}, \mathrm{Ce}, \mathrm{Zr})$," Journal of Physics, vol. 65, no. 4, pp. 641-645, 2005.

[5] W. Ren, Z. Ai, F. Jia, L. Zhang, X. Fan, and Z. Zou, "Low temperature preparation and visible light photocatalytic activity of mesoporous carbon-doped crystalline $\mathrm{TiO}_{2}$," Applied Catalysis B: Environmental, vol. 69, no. 3-4, pp. 138-144, 2007.

[6] C. Yan, X. Mei, W. He, and S. Zheng, "Present situation of residue pollution of mulching plastic film and controlling measures," Transactions of the Chinese Society of Agricultural Engineering, vol. 22, no. 11, pp. 269-272, 2006.

[7] P. Mormile, L. Petti, M. Rippa, B. Immirzi, M. Malinconico, and G. Santagata, "Monitoring of the degradation dynamics of agricultural films by IR thermography," Polymer Degradation and Stability, vol. 92, no. 5, pp. 777-784, 2007.

[8] A. Sharma and A. Sharma, "Degradation assessment of low density polythene (LDP) and polythene (PP) by an indigenous isolate of Pseudomonas stutzeri," Journal of Scientific and Industrial Research, vol. 63, no. 3, pp. 293-296, 2004.

[9] S.-Y. Lee, J.-H. Yoon, J.-R. Kim, and D.-W. Park, "Degradation of polystyrene using clinoptilolite catalysts," Journal of Analytical and Applied Pyrolysis, vol. 64, no. 1, pp. 71-83, 2002.

[10] S. H. Kim, S.-Y. Kwak, and T. Suzuki, "Photocatalytic degradation of flexible $\mathrm{PVC} / \mathrm{TiO}_{2}$ nanohybrid as an eco-friendly alternative to the current waste landfill and dioxin-emitting incineration of post-use PVC," Polymer, vol. 47, no. 9, pp. 3005-3016, 2006.

[11] S. Chakrabarti, B. Chaudhuri, S. Bhattacharjee, P. Das, and B. K. Dutta, "Degradation mechanism and kinetic model for photocatalytic oxidation of PVC-ZnO composite film in presence of a sensitizing dye and UV radiation," Journal of Hazardous Materials, vol. 154, no. 1-3, pp. 230-236, 2008.

[12] J. Shang, M. Chai, and Y. Zhu, "Solid-phase photocatalytic degradation of polystyrene plastic with $\mathrm{TiO}_{2}$ as photocatalyst," Journal of Solid State Chemistry, vol. 174, no. 1, pp. 104-110, 2003.

[13] X. U. Zhao, Z. Li, Y. Chen, L. Shi, and Y. Zhu, "Solid-phase photocatalytic degradation of polyethylene plastic under UV and solar light irradiation," Journal of Molecular Catalysis A, vol. 268, no. 1-2, pp. 101-106, 2007.

[14] G. L. Liu, D. W. Zhu, S. J. Liao, L. Y. Ren, J. Z. Cui, and W. B. Zhou, "Solid-phase photocatalytic degradation of polyethylene-goethite composite film under UV-light irradiation," Journal of Hazardous Materials, vol. 172, no. 2-3, pp. 1424-1429, 2009.

[15] M. A. Behnajady, N. Modirshahla, and M. Shokri, "Enhancement of photocatalytic activity of $\mathrm{TiO}_{2}$ nanoparticles by silver doping: photo deposition versus liquid impregnation methods," Global NEST Journal, vol. 10, pp. 1-7, 2008.
[16] M. H. Habibi, M. N. Esfahani, and T. A. Egerton, "Photochemical characterization and photocatalytic properties of a nanostructure composite $\mathrm{TiO}_{2}$ film," International Journal of Photoenergy, vol. 2007, Article ID 13653, 8 pages, 2007.

[17] F. Fallania, G. Ruggeria, and S. Broncoc, "Modification of surface and mechanical properties of polyethylene by photoinitiated reactions," Polymer Degradation and Stability, vol. 82, pp. 257-261, 2003.

[18] M. Scoponi, S. Cimmino, and M. Kaci, "Photo-stabilisation mechanism under natural weathering and accelerated photooxidative conditions of LDPE films for agricultural applications," Polymer, vol. 41, no. 22, pp. 7969-7980, 2000.

[19] W.-C. Hung, Y.-C. Chen, H. Chu, and T.-K. Tseng, "Synthesis and characterization of $\mathrm{TiO}_{2}$ and $\mathrm{Fe} / \mathrm{TiO}_{2}$ nanoparticles and their performance for photocatalytic degradation of 1,2dichloroethane," Applied Surface Science, vol. 255, no. 5, pp. 2205-2213, 2008.

[20] X. Zhao, Z. Li, Y. Chen, L. Shi, and Y. Zhu, "Enhancement of photocatalytic degradation of polyethylene plastic with CuPc modified $\mathrm{TiO}_{2}$ photocatalyst under solar light irradiation," Applied Surface Science, vol. 254, no. 6, pp. 1825-1829, 2008. 

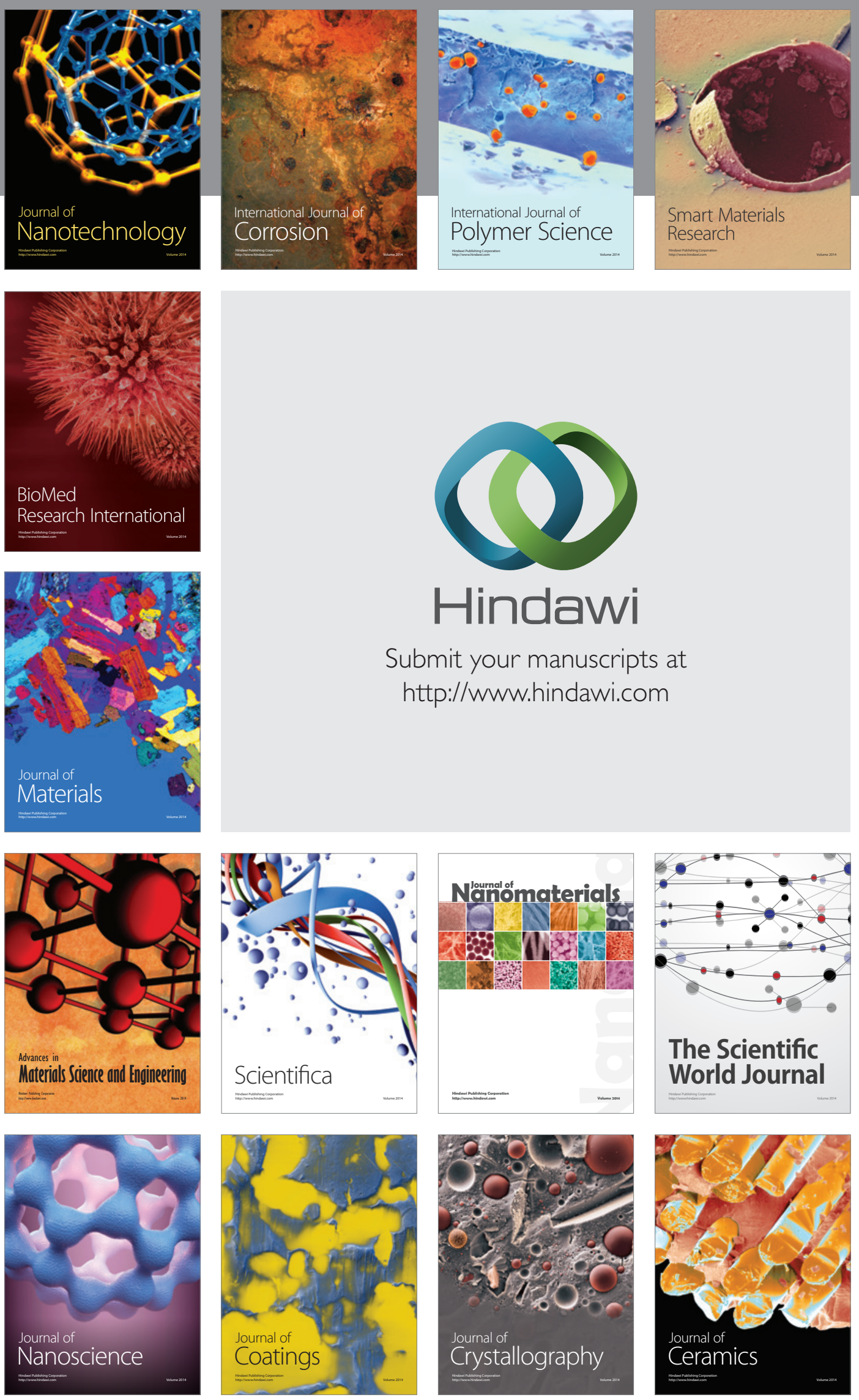

The Scientific World Journal

Submit your manuscripts at

http://www.hindawi.com

\section{World Journal}

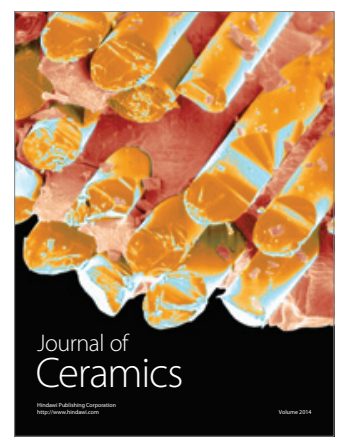

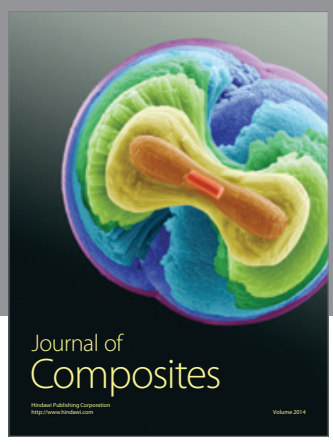
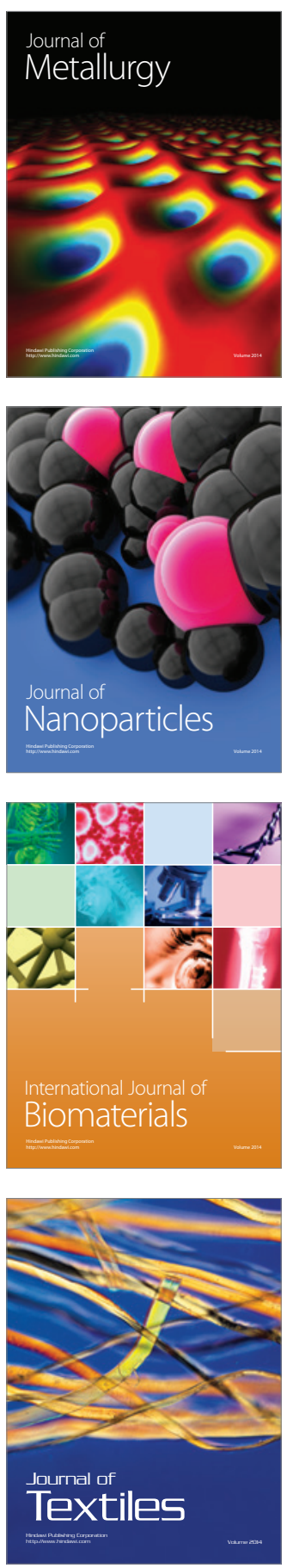